\title{
Follow-up and treatment pattern during Ramadan and evaluation of the outcome of Ramadan fasting on clinical, biochemical and metabolic parameters in patients with type 2 diabetes mellitus: a real- world, multi-center, prospective observational study
} Qureshi NKa ${ }^{a}$ Akter N ${ }^{b}$, Latif ZAc

\begin{abstract}
Background: There are variable effects of Ramadan fasting on clinical and biochemical variables of diabetic people. Anti-diabetic agents are often adjusted during this time to reflect changes in lifestyle. The study was conducted to understand the diversity of follow-up, treatment pattern, clinical, and biochemical outcome of Ramadan fasting among type 2 diabetic patients who observed Ramadan fast.

Methods: This real-world, multi-center, prospective, observational study was conducted at the diabetes outpatient department of National Healthcare Network (NHN) Uttara Center of Bangladesh Diabetic Somity (BADAS), Dhaka, Bangladesh and outpatient department of MARKS Hormone and Diabetes clinic, MARKS Medical College \&Hospital in Dhaka, Bangladesh upon randomly selected type 2 diabetic patients, recruited 1 to 12 weeks prior to the Ramadan and followed up till 12 weeks post-Ramadan period. Finally, a total of 271 participants completed satisfactory follow up. Data was collected before, during, and after Ramadan using a set of questionnaires in a face to face interview.
\end{abstract}

Results: The majority (80.1\%) of participants received pre-Ramadan education, counseling, adjustment of medication and other direction to help them cope with Ramadan fasting. A significant reduction of weight, body mass index (BMI)) and blood pressure were reported after Ramadan fast $(p<0.001)$. None of the studied participants experienced severe hyper/hypoglycemia or acute complications requiring hospitalization or an emergency room visit. Metformin was the commonest prescribed anti-diabetic medication. Premixed insulin was the commonest insulin regimen during study period. Three most commonly adjusted oral anti-diabetic drugs were gliclazide, glimepiride, metformin and insulin doses were also adjusted. Mean of fasting and prandial capillary blood glucose decreased from pre-Ramadan period to post-Ramadan period $(P<0.05)$. $H b$ Alc decreased during post-Ramadan period compared to pre-Ramadan visit $(P=0.13)$. A significant reduction in the triglyceride level was observed during post-Ramadan follow up $(P<0.05)$.

Conclusion: The study revealed that a safe fasting can be observed with proper pre-Ramadan work-up. Ramadan fasting resulted into significant reduction of weight, BMI, blood pressure, lipid profile and improved glycemic status in patients with type 2 diabetes.

Key words: Ramadan outcome, diabetes treatment pattern, type 2 diabetes mellitus.

(BIRDEM Med J 2021; 11(1): 30-38)

Author information

a. Nazmul Kabir Qureshi, Director \& Consultant (Endocrinology \& Medicine), NHN Uttara, Dhaka, Bangladesh.

b. Nazma Akter, Assistant Professor (Endocrinology \& Metabolism), MARKS Medical College \& Hospital, Dhaka, Bangladesh.

c. Zafar Ahmed Latif, Professor of Endocrinology, BIRDEM General Hospital, Dhaka, Bangladesh.

Address of correspondence: Nazmul Kabir Qureshi, Director \& Consultant (Endocrinology \& Medicine), NHN Uttara, House 2, Road 13, Sector 4, Uttara, Dhaka 1230, Bangladesh. Email: qureshinaz@yahoo.com

Received: June 28, 2020

Revision received: July 31, 2020

Accepted: October 31, 2020 


\section{INTRODUCTION}

It is obligatory on all healthy Muslim adults to fast during Ramadan. Sick people who can be adversely affected by fasting, are exempted from this according to the Holy Qur'an. ${ }^{1}$ However, patients who are prone to develop hypoglycemia and hyperglycemia, many still insist on performing Ramadan fasting. It is estimated that 50 million people with diabetes fast each year ${ }^{2}$ and majority of them lives in Asia-Pacific, Middle East, North Africa region and rest in Europe, North and South America. ${ }^{3}$

Fasting during Ramadan requires abstinence for eating, drinking and smoking from dawn to sunset. Length of the fast varies from 11 to 20 hours, depending on season and geographical locations. Moreover, changes in sleep pattern, eating habit, physical activities can potentially induce metabolic alterations in both healthy and diseased Muslims. ${ }^{4}$ The overall calorie consumption of individuals with type 2 diabetes has been reported to increase during Ramadan. ${ }^{5}$ Moreover, the doses of antidiabetic agents are often adjusted during this time to reflect the changes in lifestyle. ${ }^{6}$

The Ramadan Education and Awareness in Diabetes study READ was a retrospective study that assessed safety of Ramadan fasting on Muslims with type 2 diabetes who attended a structured educational program that included education regarding physical activity, meal plan, glucose monitoring, hypoglycemia, dosing and timing of medication. The study revealed that total number of hypoglycemic events was significantly less among patients those had structured education in the pre-Ramadan period. ${ }^{7}$ There are also variable evidences of effects of Ramadan fasting on biochemical variables of diabetic people. ${ }^{8}$

However, pragmatic prospective studies evaluating clinically relevant events in diabetic patients who fast are relatively scarce. Most of the studies are either smallscaled, recruiting even fewer than 60 subjects or retrospective. ${ }^{9,1011,12}$ This study was designed to fill this gap. The main objectives of this prospective study were:

- to understanding the diversity of follow-up and treatment pattern of patients with Type 2 Diabetes Mellitus (T2DM) during Ramadan;

- to evaluate the effects of Ramadan fasting on clinical, biochemical and metabolic parameters in T2DM patients;

- to determine the proportion of diabetic patients who develop hypo/hyperglycemic episodes, need hospitalization or an emergency room visit due to adverse events while fasting during the month of Ramadan.

\section{METHODS}

\section{Study design}

This was a real-world, multi-center, prospective, observational study conducted at the Diabetes outpatient department of National Healthcare Network (NHN) Uttara Center of Bangladesh Diabetic Somity (BADAS), Dhaka, Bangladesh and outpatient department of MARKS Hormone and Diabetes clinic, MARKS Medical College \& Hospital in Dhaka, Bangladesh. Potential adult patients having T2DM were screened and approached to determine their interest in participating in this study before Ramadan. Upon consent, a pre-formed data record form was used to collect data in a face to face interview including investigation reports those done before, during, and after Ramadan.

\section{Study period}

The study was carried out from January 2017 to December of 2017. Literature review and formulation of study design was done during January-February of 2017. Study sample enrollment started from March of 2017. Data were collected during March to October of same year. Data was processed and analyzed during November-December of 2017.

\section{Study sample}

Initially 345 subjects were recruited. Finally, a total of 271 participants completed satisfactory follow up and were studied.

\section{Eligibility criteria}

Patients over 25 years of age having type 2 diabetes mellitus for more than a year, who were willing to take part in the study, were included. The patients who were not willing to take part in the study, pregnant and lactating women, having T1DM, having current acute illness, those who received short term corticosteroid therapy were excluded from the study.

\section{Study tools and operational definitions}

a. Data record form: The data record form used in this study encompassed a section on sociodemographic and clinical information of participants that included age, gender, level of 
education, employment status, body mass index, duration of diabetes, complications and comorbidities. Another section included information on types of anti-diabetic agents used and dose regimens, adjustments made to the medication during Ramadan. Outcome measures, such as blood glucose profile, HbA1c, liver enzymes, s. creatinine, and lipid profile were collected before and after Ramadan. The studied participants were also asked about any event of hypoglycemia or hyperglycemia, dehydration and others complication or illness during Ramadan fasting and whether they had to visit an emergency room or required hospitalization due to adverse glycemic events during study period.

b. Self-monitoring of blood glucose (SMBG): Following SMBG Protocol was provided with participants: to check capillary blood glucose preSuhoor, early morning 2 to 4 hours after Suhoor, mid-day between 11 am to $1 \mathrm{pm}$, pre-Iftar, 2-hours after Iftar, at any time when there were symptoms of hypoglycemia / hyperglycemia or feeling unwell. Subjects with very high risk/high risk who fasted against medical advice, SMBG were advised for multiple times of day. Moderate and low risk patients were instructed to monitor their blood sugar, at the following times: pre-Suhoor, midday, pre-Iftar, 2-hour post-Iftar or whenever symptoms of hypoglycemia or acute illness occur. ${ }^{13}$

c. Hypoglycemia: It has been defined as plasma glucose value $\leq 70 \mathrm{mg} / \mathrm{dL}(\leq 3.9 \mathrm{mmol} / \mathrm{L})$ and severe hypoglycemia is defined as event of hypoglycemia characterized by altered mental and or physical status requiring assistance for recovery. ${ }^{14}$

d. Hyperglycemia: Hyperglycemia is the term for high blood glucose that happens when the body has too little insulin or when the body can't use insulin properly. ${ }^{15}$

e. Diabetic Ketoacidosis (DKA): A blood glucose $>250 \mathrm{mg} / \mathrm{dl}$ (13.9 mmol/L), moderate degree of ketonemia and/or ketonuria, an arterial $\mathrm{pH}<7.3$, a serum bicarbonate (HCO3-) $<15 \mathrm{mEq} / \mathrm{L}$ and an increased anion gap metabolic acidosis define diagnosis of DKA. ${ }^{16}$

f. Dehydration: Mild to moderate dehydration was defined through dry mouth/tongue, thirst, headache, lethargy, fatigue, dry skin, muscle weakness, lightheadedness, dizziness and a lack of focus. Severe dehydration was defined through sunken eyes, lack of tears, hypotension, tachycardia and, in the worstcase scenario, unconsciousness. ${ }^{17,18}$

g. Instruction on when to break the fast: Participants were instructed to break the fast when blood glucose was $<3.9 \mathrm{mmol} / \mathrm{L}$ or $\leq 16.7 \mathrm{mmol} / \mathrm{L}$, if they felt unwell, experienced symptoms of hypoglycemia and during acute illness. ${ }^{19}$

\section{Data record procedure}

Data of each participant was recorded at three visits. The first Pre-Ramadan visit was recorded from or before twelve weeks until one week prior to onset of Ramadan (visit-1), the second Ramadan visit was made during the month of Ramadan (visit-2), and the third PostRamadan visit was recorded starting from one week up to twelve weeks after end of Ramadan (visit-3). The data record form was completed by the trained interviewers.

During Pre-Ramadan visit (visit-1), the sociodemographic, clinical and biochemical profile of studied participants were recorded. Structured education on symptoms of hypoglycemia hyperglycemia, DKA, dehydration, other possible complications, SMBG protocol, when should break the fast, diet plan and exercise advice were delivered. Blood samples were collected for baseline investigations. The participants were requested to measure their capillary blood glucose levels using a glucometer. The values were charted by the patients and were later recorded during subsequent visit. The participants were also requested to report any hypo/hyperglycemic or other events e.g.; visit to emergency room or hospitalization. As per standard Ramadan recommendation, anti-diabetic medications were adjusted.

During Ramadan follow-up (visit-2), along with SMBG records, any event of hypoglycemia or hyperglycemia, dehydration and others complication or illness during Ramadan fasting and visit to emergency room or hospitalization due to adverse glycemic events were recorded.

During Post-Ramadan visit (visit-3), clinical and biochemical profiles of participants were reviewed and final outcome were measured.

\section{Statistical analysis}

Data were analyzed using IBM SPSS for Windows version 20.0(IBM SPSS Statistics for Windows, Version 20.0IBM Corp. Armonk, NY, USA). Frequencies and percentages were calculated for quantitative variables, while mean $\pm \mathrm{SD}$ were documented for qualitative variables. Categorical variables were compared with 
each other using the chi-square test. Among the basic characteristics of the studied participants, the continuous variables were compared with each other using the ANOVA test. For parametric parameters both one sampled and paired $t$ test was used to analyze the changes in clinical and biochemical parameters before and after Ramadan. Statistical significance was set at $\mathrm{P}<0.05$.

\section{RESULTS}

\section{Studied participants characteristics}

A total of 271 patients with Type 2 DM, age ranging from 27 to 84 years participated in this study which included 128 men and 143 women with a sex ratio of 0.89 . Mean of duration of diabetes of participants was $6.28 \pm 10.15$ years (Table I). A large majority $(n=160$; $59.0 \%$ ) of the studied subjects had at least up to 12 th grade education and $45 \%$ of the participants were homemaker ( $\mathrm{n}=123 ; 45.38 \%$, all of them were female). Majority $(n=143 ; 86 \%)$ of the studied participants had co-morbidities and diabetes related chronic complications. Clinical parameter studied during preRamadan and post-Ramadan period is mentioned in Table II. Few participants had history of hypoglycemia $(1.1 \%)$ and keto-acidosis (3.7\%) at least three months prior Ramadan (Table III).

Table I Socio-demographic parameter of studied subjects $(\mathrm{N}=271)$

\begin{tabular}{llcccc}
\hline Variables & & $\begin{array}{c}\text { Total } \\
(\mathrm{N}=271)\end{array}$ & $\begin{array}{c}\text { Male } \\
(\mathrm{n}=128)\end{array}$ & $\begin{array}{c}\text { Female } \\
(\mathrm{n}=143)\end{array}$ & p value \\
\hline Age $(\mathrm{yrs})(\mathrm{Mean} \pm \mathrm{SD})$ & $43.31 \pm 10.26$ & $48.65 \pm 10.60$ & $46.10 \pm 9.82$ & 0.04 & \\
Duration of DM (yrs) (Mean $\pm \mathrm{SD})$ & $6.28 \pm 10.15$ & $5.85 \pm 4.56$ & $6.66 \pm 13.31$ & 0.51 & \\
Education[N (\%)] & $<$ S.S.C & $111(41.0)$ & $35(27.34)$ & $76(53.14)$ & 0.000 \\
& >S.S.C & $160(59.0)$ & $93(72.65)$ & $67(46.85)$ & \\
Occupation[N (\%)] & Service Holder & $81(29.9)$ & $72(56.25)$ & $9(6.29)$ & 0.000 \\
& Businessman & $19(7.01)$ & $18(14.06)$ & $1(0.69)$ & \\
& Retired & $48(17.71)$ & $38(26.68)$ & $10(86.01)$ & \\
& Homemaker & $123(45.38)$ & $0(0.0)$ & $123(45.38)$ & \\
\hline
\end{tabular}

SSC: Secondary School Certificate; ANOVA and Chi-square analysis were done.

Table II Clinical parameter differences during pre-Ramadan and post-Ramadan period ( $\mathrm{N}=271)$

\begin{tabular}{lccccccc}
\hline Variables & \multicolumn{3}{c}{ Before Ramadan } & \multicolumn{3}{c}{ After Ramadan } & P value \\
& Mean \pm SD & S.E. mean & $t$ value & Mean \pm SD & S.E. mean & $t$ value \\
\hline Weight $(\mathrm{kg})$ & $64.71 \pm 9.96$ & 0.60 & 106.87 & $64.37 \pm 9.72$ & 0.59 & 108.94 & 0.000 \\
BMI $\left(\mathrm{kg} / \mathrm{m}^{2}\right)$ & $26.42 \pm 4.91$ & 0.29 & 88.44 & $26.29 \pm 4.07$ & 0.24 & 106.15 & 0.000 \\
SBP $(\mathrm{mm} \mathrm{Hg})$ & $126.77 \pm 14.39$ & 0.87 & 144.97 & $121.07 \pm 9.27$ & 0.57 & 208.89 & 0.000 \\
DBP $(\mathrm{mm} \mathrm{Hg})$ & $79.44 \pm 7.38$ & 0.44 & 177.14 & $78.35 \pm 5.56$ & 0.34 & 225.14 & 0.000 \\
\hline
\end{tabular}

BMI: body mass Index; SBP: systolic Blood Pressure; DBP: diastolic Blood Pressure; One Samples $t$ Test was done.

Table III Pre-Ramadan assessment of studied subjects $(\mathrm{N}=271)$

\begin{tabular}{llccccccc}
\hline Variables & Total $(\mathrm{N}=271)$ & \multicolumn{2}{c}{ Male $(\mathrm{N}=128)$} & Female $(\mathrm{N}=143)$ & $\mathrm{p}$ value \\
& & $\mathrm{n}$ & $\%$ & $\mathrm{n}$ & $\%$ & $\mathrm{n}$ & $\%$ & \\
Pre-Ramadan & Present year & 217 & 80.10 & 99 & 77.34 & 118 & 82.51 & 0.287 \\
Counseling & Past year & 54 & 19.90 & 29 & 22.65 & 25 & 17.48 & \\
Hypoglycemia & No & 268 & 98.0 & 126 & 98.43 & 142 & 99.30 & 0.498 \\
& 3 months prior Ramadan & 3 & 1.1 & 2 & 1.56 & 1 & 0.69 & \\
Keto-acidosis & No & 261 & 96.3 & 123 & 96.09 & 138 & 96.50 & 0.335 \\
& 3 months prior Ramadan & 10 & 3.7 & 5 & 2.34 & 5 & 3.49 & \\
\hline
\end{tabular}

Chi-square analysis was done 


\section{Diversity of peri-Ramadan follow-up}

The majority ( $80.1 \%$ ) received pre-Ramadan education and counseling on medication adjustment, meal, exercise, when to break fasting rules, SMBG etc. However, all of them $(100.0 \%)$ went for a medication review prior one to twelve weeks or more by their physician before they began fasting. Pattern of follow up during pre-Ramadan and post-Ramadan period is mentioned in Table IV. Only $26.2 \%$ of participants did practice regular self-monitoring of blood glucose (SMBG) during Ramadan while rest (73.2\%) did not (Table V). In this study, none of the studied participant experienced severe hypo/hyperglycemia requiring hospitalization or an emergency room visit. Few developed dehydration and fever during Ramadan fasting period $(3.70 \% \& 2.20 \%$ respectively) (Table $\mathrm{V}$ ).

Table IV Follow up pattern during pre-Ramadan and post-Ramadan period ( $\mathrm{N}=271)$

\begin{tabular}{|c|c|c|c|c|c|c|c|c|}
\hline \multirow[t]{3}{*}{ Variables } & \multicolumn{4}{|c|}{ Pre-Ramadan } & \multicolumn{4}{|c|}{ Post-Ramadan } \\
\hline & Total & Male & Female & p & Total & Male & Female & p \\
\hline & & & & & & & & \\
\hline Followup & No & $0(0.0)$ & $0(0.0)$ & $0(0.0)$ & 0.11 & $14(5.20)$ & $8(6.25)$ & $6(4.19) \quad 0.21$ \\
\hline (week) & $<1$ Week & $29(10.70)$ & $20(15.62)$ & $9(6.29)$ & & $10(3.70)$ & $7(5.46)$ & $3(2.09)$ \\
\hline 1-2 Week & $115(42.40)$ & $48(37.50)$ & $67(46.85)$ & & & $58(21.40)$ & $32(25.0)$ & $26(18.18)$ \\
\hline \multirow[t]{2}{*}{ 2-4 Week } & $95(35.10)$ & $43(33.59)$ & $52(36.36)$ & & & $148(54.60)$ & $62(48.43)$ & $86(60.13)$ \\
\hline & 4-12 Week & $26(9.60)$ & $14(10.93)$ & $12(8.39)$ & & $41(15.10)$ & $19(14.84)$ & $22(15.38)$ \\
\hline$>12$ Week & $6(2.20)$ & $3(2.34)$ & $3(2.09)$ & & & $0(0.0)$ & $0(0.0)$ & $0(0.0)$ \\
\hline
\end{tabular}

Chi-square analysis was done.

Table V Pattern of follow-up, SMBG and complication during Ramadan among subjects ( $\mathrm{N}=271)$

\begin{tabular}{|c|c|c|c|c|c|c|c|c|}
\hline \multirow[t]{2}{*}{ Variables } & & \multicolumn{2}{|c|}{ Total $(\mathrm{N}=271)$} & \multicolumn{2}{|c|}{ Male $(n=128)$} & \multicolumn{2}{|c|}{ Female $(\mathrm{n}=143)$} & \multirow[t]{2}{*}{$P$ value } \\
\hline & & $\mathrm{n}$ & $\%$ & $\mathrm{n}$ & $\%$ & $\mathrm{n}$ & $\%$ & \\
\hline Follow-up & No & 12 & 4.40 & 9 & 7.03 & 3 & 2.09 & 0.27 \\
\hline during & $1^{\text {st }}$ Week & 70 & 25.80 & 36 & 28.12 & 34 & 23.77 & \\
\hline Ramadan & $2^{\text {nd }}$ Week & 167 & 61.60 & 73 & 57.03 & 94 & 65.73 & \\
\hline \multirow[t]{2}{*}{ (Week) } & $3^{\text {rd }}$ Week & 14 & 5.20 & 6 & 4.68 & 8 & 5.59 & \\
\hline & $4^{\text {th }}$ Week & 8 & 3.0 & 4 & 3.12 & 4 & 2.79 & \\
\hline SMBG & No & 200 & 73.80 & 91 & 71.09 & 109 & 76.22 & 0.403 \\
\hline \multirow[t]{4}{*}{ (Week) } & $1^{\text {st }}$ Week & 29 & 10.70 & 13 & 10.15 & 16 & 11.18 & \\
\hline & $2^{\text {nd }}$ Week & 36 & 13.30 & 19 & 14.84 & 17 & 11.88 & \\
\hline & $3^{\text {rd }}$ Week & 5 & 1.80 & 4 & 3.12 & 1 & 0.69 & \\
\hline & $4^{\text {th }}$ Week & 1 & 0.4 & 1 & 0.78 & 0 & 0.0 & \\
\hline Complication & No Complication & 265 & 97.80 & 124 & 96.87 & 141 & 98.60 & 0.335 \\
\hline During & Dehydration & 10 & 3.70 & 3 & 2.34 & 7 & 4.89 & \\
\hline Ramadan & Fever & 6 & 2.20 & 4 & 3.12 & 2 & 1.39 & \\
\hline \multirow{2}{*}{\multicolumn{2}{|c|}{$\begin{array}{l}\text { Hospitalization/Emergency room } \\
\text { visit due to severe Hypo/ } \\
\text { hyperglycemia }\end{array}$}} & 0 & 0.0 & 0 & 0.0 & 0 & 0.0 & \\
\hline & & & & & & & & \\
\hline
\end{tabular}

SMBG: Self Monitoring of Blood Glucose; Chi-square analysis was done. 


\section{Treatment pattern during Ramadan}

Metformin was the commonest prescribed anti-diabetic medication all through the pre [232(85.60\%)] to post [234 (86.30\%)] Ramadan follow-up; used alone or in combination with other oral anti-diabetic drugs (OADs) or insulin. A good number of participants were managed with sulfonylurea (most frequent are gliclazide and glimepiride) alone or in combination with other OADs or insulin during both pre [169(62.4\%)] and post [166 $(61.30 \%)]$ Ramadan follow-up. Premixed insulin was the commonest insulin regimen during study period. Prescribed Insulin regimen alone or with OADs were as following: premixed insulin [pre vs. Post Ramadan: $69(25.50 \%)$ vs. $64(23.60 \%)]$, basal insulin concurrently with mealtime insulin [pre vs. Post Ramadan: $34(12.50 \%)$ vs. $35(12.90 \%)]$.

\section{Dose adjustment pattern of anti-diabetic medications during Ramadan}

This study showed that, the three most commonly adjusted OADs were metformin, gliclazide and glimepiride with mean dose of $1020.60 \pm 350.68 \mathrm{mg}$, $76.47 \pm 27.05 \mathrm{mg}$ and $2.25 \pm 9.65 \mathrm{mg}$ respectively during Ramadan (all dose were reduced); and 1088.0 \pm 686.46 $\mathrm{mg}, 102.63 \pm 40.47 \mathrm{mg}$ and $3.97 \pm 19.50 \mathrm{mg}$ respectively after Ramadan. Patients were treated with a stable dose of DPP4 inhibitors (sitagliptin and vildagliptin) throughout the studied period. The mean of dose (with reduction) of insulin for premixed and basal insulin were: $32.08 \pm 9.22$ units and $15.0 \pm 4.21$ unit respectively during Ramadan period while $63.55 \pm 88.58$ units (increased dose) and $18.96 \pm 4.39$ unit (increase) respectively after Ramadan period (Table VI\&VII).

Table VI Mean daily dose of OADs and insulin before and during Ramadan

\begin{tabular}{llllccccc}
\hline Treatment Modalities & \multicolumn{2}{c}{ Before Ramadan } & During Ramadan & \multicolumn{3}{c}{ Paired $t$ Test } & sig \\
& & Mean \pm SD & S.E. mean & Mean \pm SD & S.E. mean & & & $\begin{array}{c}\text { (two- } \\
\text { tailed) }\end{array}$ \\
\hline OAD (daily & Gliclazide & $101.18 \pm 40.47$ & 4.00 & $76.47 \pm 27.05$ & 2.67 & 7.71 & 101 & 0.000 \\
dose in mg) & Glimepiride & $3.95 \pm 19.36$ & 2.36 & $2.25 \pm 9.65$ & 1.17 & 1.43 & 66 & 0.157 \\
& Metformin & $1099.80 \pm 893.17$ & 58.51 & $1020.60 \pm 350.68$ & 22.97 & 1.50 & 232 & 0.135 \\
& DPP4 in. & $53.95 \pm 19.94$ & 2.21 & $54.56 \pm 20.58$ & 2.28 & -1.00 & 80 & 0.320 \\
Insulin (daily & Premixed & $42.17 \pm 12.23$ & 1.47 & $32.08 \pm 9.22$ & 1.11 & 11.08 & 68 & 0.000 \\
dose in Unit) Basal & $19.47 \pm 5.51$ & 0.94 & $15.00 \pm 4.21$ & 0.72 & 5.67 & 33 & 0.000 \\
& Bolus & $34.22 \pm 12.82$ & 4.27 & $58.33 \pm 77.85$ & 25.95 & -0.973 & 8 & 0.359 \\
\hline
\end{tabular}

OADs: Oral Anti-diabetic Drugs; DPP4in: Di-Peptidyl-peptidase 4 inhibitors; Paired Samples $t$ Test was done

Table VII Mean daily dose of OADs and insulin before and after Ramadan

\begin{tabular}{llllllllc}
\hline Treatment Modalities & \multicolumn{2}{c}{ Before Ramadan } & \multicolumn{2}{c}{ After Ramadan } & $t$ value & $d f$ & $\begin{array}{c}\text { sig } \\
\text { (two- }\end{array}$ \\
& & Mean \pm SD & S.E. mean & Mean \pm SD & S.E. mean & & & tailed) \\
\hline OAD(daily & Gliclazide & $100.20 \pm 40.15$ & 4.06 & $102.63 \pm 40.47$ & 2.67 & -1.179 & 98 & 0.241 \\
dose in mg) & Glimepiride & $3.96 \pm 19.51$ & 2.40 & $3.97 \pm 19.50$ & 2.40 & -0.184 & 65 & 0.854 \\
& Metformin & $1093.30 \pm 898.78$ & 59.39 & $1088.0 \pm 686.46$ & 45.36 & 0.079 & 228 & 0.937 \\
& DPP4 in. & $53.50 \pm 19.75$ & 2.25 & $54.15 \pm 20.44$ & 2.33 & -1.00 & 76 & 0.320 \\
Insulin(daily & Premixed & $42.69 \pm 11.81$ & 1.48 & $63.55 \pm 88.58$ & 11.16 & -1.894 & 62 & 0.063 \\
dose in Unit) & Basal & $19.33 \pm 5.53$ & 0.96 & $18.96 \pm 4.39$ & 0.76 & 0.516 & 32 & 0.609 \\
& Bolus & $33.25 \pm 13.34$ & 4.71 & $38.00 \pm 18.17$ & 6.42 & -1.245 & 7 & 0.253 \\
\hline
\end{tabular}

OADs: Oral Anti-diabetic Drugs; DPP4in: Di-Peptidyl-Peptidase 4 inhibitors; Paired Samples $t$ Test was done 
Table VIII Differences of glycemic and other biochemical parameters before and after Ramadan of studied subjects

\begin{tabular}{|c|c|c|c|c|c|c|c|c|}
\hline \multicolumn{2}{|c|}{ Biochemical and glycemic } & \multicolumn{2}{|c|}{ Before Ramadan } & \multirow{2}{*}{$\begin{array}{l}\text { After Ramadan } \\
\text { S.E. mean }\end{array}$} & & \multicolumn{2}{|l|}{ Paired $t$ Test } & \multirow{2}{*}{$\begin{array}{c}\text { Sig } \\
\text { (two- } \\
\text { tailed) }\end{array}$} \\
\hline parameters & Mean \pm SD & S.E. mean & Mean \pm SD & & & $t$ value & $d f$ & \\
\hline Blood & FBG & $9.27 \pm 4.31$ & 0.29 & $8.46 \pm 2.67$ & 0.18 & 2.54 & 210 & 0.012 \\
\hline glucose & $2 \mathrm{~h} \mathrm{ABF}$ & $12.58 \pm 4.12$ & 0.28 & $11.12 \pm 3.37$ & 0.23 & 5.35 & 209 & 0.000 \\
\hline Profile & $\mathrm{HbAlc}$ & $8.95 \pm 1.95$ & 0.48 & $8.09 \pm 1.45$ & 0.36 & 1.58 & 15 & 0.134 \\
\hline $\begin{array}{l}\text { Liver } \\
\text { Enzymes }\end{array}$ & ALT & $51.10 \pm 18.10$ & 5.70 & $45.60 \pm 11.70$ & 3.70 & 0.94 & 9 & 0.368 \\
\hline $\begin{array}{l}\text { Renal } \\
\text { Function Test }\end{array}$ & S. Creatinine & $0.98 \pm 0.25$ & 0.07 & $0.92 \pm 0.20$ & 0.06 & 1.21 & 10 & 0.251 \\
\hline $\begin{array}{l}\text { Lipid } \\
\text { Profiles }\end{array}$ & $\begin{array}{l}\text { Total } \\
\text { Cholesterol }\end{array}$ & $199.50 \pm 33.65$ & 10.64 & $182.20 \pm 29.32$ & 9.27 & 1.97 & 9 & 0.08 \\
\hline & HDL & $35.77 \pm 4.76$ & 1.58 & $39.88 \pm 3.21$ & 1.07 & -2.09 & 8 & 0.069 \\
\hline & LDL & $114.50 \pm 26.46$ & 7.63 & $100.42 \pm 25.73$ & 7.42 & 2.12 & 11 & 0.057 \\
\hline & TG & $159.08 \pm 56.85$ & 16.41 & $101.33 \pm 63.95$ & 18.46 & 3.49 & 11 & 0.005 \\
\hline
\end{tabular}

FBS: Fasting Blood Glucose (mmol/L); 2h ABF: 2-hour After Breakfast (mmol/L); ALT: Alanine Aminotransferase (U/L); HDL: High Density Lipoprotein (mg/dl); LDL: Low Density Lipoprotein (mg/dl); TG: Triglyceride (mg/dl); HbAlc in \%. Paired Samples $t$ Test was done.

\section{Outcome of Ramadan fasting on clinical parameters}

As with BMI $\left(\mathrm{kg} / \mathrm{m}^{2}\right)$, significant reduction of body weight was recorded after Ramadan fasting in comparison to pre-Ramadan period $(\mathrm{p}<0.001)$. There was significant reduction of both systolic and diastolic blood pressure during post-Ramadan follow up $(\mathrm{p}<0.001)$ (Table II).

Outcome of Ramadan fasting on biochemical parameters

Mean of fasting capillary blood glucose decreased significantly from pre-Ramadan period to post-Ramadan period $(9.27 \pm 4.31 \mathrm{mmol} / \mathrm{L}$ vs. $8.46 \pm 2.67 \mathrm{mmol} / \mathrm{L}$; $\mathrm{P}<0.05$ ) and prandial blood glucose showed similar trend $(\mathrm{P}<0.05)$. HbA1c decreased during post-Ramadan visit compared to pre-Ramadan visit ( $8.09 \%$ vs. $8.95 \%$ respectively; $\mathrm{P}=0.13$ ). Mean of serum creatinine of studied participants varied slightly from pre- Ramadan to post-Ramadan visit $(0.98 \pm .25 \mathrm{mg} / \mathrm{dl}$ to $0.92 \pm .20 \mathrm{mg} /$ $\mathrm{dl}$ respectively; $\mathrm{p}$ 0.25). Serum ALT value (U/L) did not show any significant change. Serum triglyceride level was notably reduced from pre-Ramadan to postRamadan visit $(159.08 \pm 56.85 \mathrm{mg} / \mathrm{dl}$ to $101.33 \pm 63.95$ $\mathrm{mg} / \mathrm{dl} ; \mathrm{P}<0.05)$. The results of the variations of biochemical parameters of studied participants have been summarized in Table VIII.

\section{DISCUSSION}

This study was conducted upon Bangladeshi type 2 diabetic subjects during the month of Ramadan to assess the pattern of follow-up, medication adjustment and impacts of fasting on clinical and biochemical indicators. The effect of Ramadan fasting on diabetic subjects has been demonstrated in various studies. ${ }^{20,21}$ This study confirmed that well-adjusted patients tolerated Ramadan fasting. Here, the mean of BMI and weight were significantly reduced after Ramadan fasting; this BMI reduction has also been found in some previous works. 22,23 This was probably due to a decrease in the number of meals (two meals instead of three meals) that contributed to reduced calories intake during Ramadan as compared to pre-Ramadan period. A significant reduction of systolic and diastolic blood pressure was recorded after Ramadan $(\mathrm{p}<0.001)$.

A pre-Ramadan visit to the physician decreased the risk of developing hypoglycemia in diabetic patients who intended to fast compared to those who did not go for a medical consultation. ${ }^{24}$ EPIDIAR study reported that $62 \%$ of patients with type 2 diabetes obtained advice from their healthcare providers before starting to fast and $2 \%$ of the patients with type 2 diabetes experienced severe hypoglycemia and $4 \%$ experienced severe hyperglycemia requiring hospitalization. ${ }^{11}$ Here, all of 
the studied participants went for a medical review by their physician before they began fasting.

Regarding use of antidiabetic drugs during Ramadan, metformin is the most prescribed one alone or in combination with other $\operatorname{drug}(\mathrm{s})$ or insulin. ${ }^{25}$ Sulphonylurea agents and other insulin secretagogue still represent as treatment modalities in Ramadan despite of risk of hypoglycemia and weight gain effects. ${ }^{26,27} \mathrm{~A}$ study conducted in North-West London among Muslim patients with Type 2 diabetes attending primary care practices, showed that appropriate treatment adjustments can lead to avoidance of significant weight gain and improved glucose control without hypoglycaemia and addition of vildagliptin to metformin therapy during Ramadan in Muslim patients with type 2 diabetes was associated with a reduction in the incidence of hypoglycaemia while compared with sulphonylurea. ${ }^{28}$ In this study, we noted that metformin and sulfonylurea was commonly prescribed anti-diabetic drugs all through the study period; used alone or in combination with other oral anti-diabetic drugs (OADs) or insulin. Gliclazide and glimepiride were the most frequently used sulfonylurea-group of drugs. In this study, patients were treated with a stable dose of DPP4 inhibitors (sitagliptin and vildagliptin) through-out the studied period This study also exhibits the use of different regimens of insulin. Premixed insulin was the commonest insulin regimen during study period. With dose adjustment, none of the studied participants experienced severe hyper/hypoglycemia requiring hospitalization or an emergency room visit.

Multiple studies have demonstrated that $\mathrm{HbA} 1 \mathrm{c}$ values do not change during Ramadan fasting. ${ }^{29,30}$ Our results revealed a reduction of the mean $\mathrm{HbA} 1 \mathrm{c}$ after Ramadan fasting, which was not statistically significant. While it has been found that after fasting, our patients had a significant decrease in FBG from 9.27 to $8.46 \mathrm{mmol} / \mathrm{L}$ and prandial blood glucose showed similar trend. A previous investigation showed that the levels of triglycerides decreased at the first week of fasting and increase later towards the end of Ramadan. ${ }^{31}$ Here, participants presented a significant reduction in the triglyceride level during post Ramadan period $(\mathrm{P}<0.05)$ while creatinine level showed a decreasing tendency $(\mathrm{P}=0.25)$.

\section{Limitations}

This study has several limitations. It had no control group. Variables such as physical activity and meal plan that can potentially affect results were not recorded. Only patients with type 2 diabetes were included. The study was conducted in urban area only. Studied participants were asked to monitor their blood glucose at home, but many patients did not follow according to schedule for various reasons such as non-compliance, belief that it may break fast, non-availability of glucometer or lack of family support.

\section{Conclusion}

This study finds that studied participants with T2DM consulted their physician for pre-Ramadan education, counseling and medication adjustment which helped in avoiding severe hypoglycemia or other acute complications during Ramadan fasting. Along with reduction of body weight, BMI, blood pressure and lipid profile, Ramadan fasting appeared to reflect beneficial effects on glycemic status of patients.

Authors' contributions: NKQ prepared study design, did data analysis, data interpretation, drafted and edited the manuscript. NA contributed to data analysis, data interpretation and manuscript preparation. ZAL developed the concept, designed the study, edited and reviewed the manuscript. All Authors read and approved the final manuscript.

Conflict of interest: Nothing to declare.

\section{REFERENCES}

1. Qur'an 2:183-5.

2. Mahmoud AI. Managing diabetes during Ramadan. Diabetes Voice 2007;52:19-22.

3. Pewforum.org [homepage on the Internet] (2014) The future of the global Muslim population: projections for 2010-30.

4. Mansi KMS. Study the effects of Ramadan fasting on the serum glucose and lipid profile among healthy Jordanian students. American Journal of Applied Sciences 2007; 4(8):565-9.

5. Vasan SK, Karol R, Mahendri NV, Arulappan N, Jacob JJ, Thomas N. A prospective assessment of dietary patterns in Muslim subjects with type 2 diabetes who undertake fasting during Ramadan. Indian Journal of Endocrinology and Metabolism 2012; 16(4): 552-7.

6. Pinelli NR, Jaber LA. Practices of Arab American patients with type 2 diabetes mellitus during Ramadan. Journal of Pharmacy Practice 2011; 24(2): 211-5. 
7. Bravis V, Hui E, Salih S, Mehar S, Hassanein M, Devendra D. Ramadan Education and Awareness in Diabetes (READ) programme for Muslims with Type 2 diabetes who fast during Ramadan. Diabet Med 2010; 27: 327-31.

8. Benaji B, Mounib N, Roky R, Aadil N, Houti IE, Moussamih $\mathrm{S}$, et al. Diabetes and Ramadan: reviewof the literature. Diabetes Res Clin Pract 2006;73:117-25.

9. Uysal AR, Erdogan MF, Sahin G, Kamel N, Erdoðan G. Clinical and metabolic effects of fasting in 41 type 2 patients during Ramadan. Diabetes Care1998; 21:2033-4.

10. Katibi IA, Akande AA, Bojuwoye BJ, Okesina AB. Blood sugar control among fasting Muslims with type 2 diabetes mellitus in Ilorin. Niger J Med 2001; 10:132-4.

11. Salti I, Benard E, Detournay B, Bianchi-Biscay M, Le Brigand C, Voinet C, et al. The EPIDIAR Study Group. A populationbased study of diabetes and its characteristics during the fasting month of Ramadan in 13 countries: results of the Epidemiology of Diabetes and Ramadan 1422/2001 (EPIDIAR) study. Diabetes Care 2004;27:2306-11.

12. Babineaux SM, Toaima D, Boye KS. Multi-country retrospective observational study of the management and outcomes of patients with Type 2 diabetes during Ramadan in 2010 (CREED). Diabet Med 2015;32:819-28.

13. Pathan MF, Sahay RK, Zargar AH, Raza SA, Khan AKA, Gaine MA, et al. South Asian Consensus Guideline: Use of insulin in diabetes during Ramadan. Indian J Endocrinol Metab 2012; 16(4): 499-502.

14. Seaquist ER, Anderson J, Childs B, Cryer P, Dagogo-Jack S, Fish L, et al. Hypoglycemia and diabetes: a report of a workgroup of the American Diabetes Association and the Endocrine Society. Diabetes Care 2013; 36:1384-95

15. 'Hyperglycemia'. American Diabetes Association.[Access Date: 2020 May 5] https://www.diabetes.org/diabetes/ medication management/ blood-glucose-testing-and-control/ hyperglycemia.

16. Kitabchi AE, Umpierrez GE, Murphy MB, Barrett EJ, Kreisberg RA, Malone JI, et al. Management of hyperglycemic crises in patients with diabetes. Diabetes Care 2001; 24:3153.

17. Popkin BM, D’Anci KE, Rosenberg IH. Water, hydration and health. Nutr Rev 2010;68(8):439-58.

18. Grandjean AC, Reimers KJ, Buyckx ME. Hydration: issues for the 21st century. Nutr Rev 2003;61(8):261-71.

19. Hassanein M, Belhadj M, Abdullah K, Bhattacharya AD, Singh AK, Tayeb K, et al. Management of Type 2 diabetes in
Ramadan: Low-ratio premix insulin working group practical advice. Indian J Endocrinol Metab 2014;18:794-9.

20. Belkhadir J, Ghomari H, Klocker N, Mikou A, NasciriM, Sabri M. Muslims with non-insulin dependent diabetes fasting during Ramadan: treatment with glibenclamide. BMJ 1993; 307(6899):292-5.

21. Hosseini SRA, Hejazi K. The effects of Ramadan fasting and physical activity on blood hematological-biochemical parameters. Iran J Med Sci 2013;16(7):845-9.

22. Hallak MH, Nomani M. Body weight loss and changes in blood lipid levels in normal men on hypocaloric diets during Ramadan fasting. Am J Clin Nutr 1988;48(5):1197-210.

23. Ziaee V, Razaei M, Ahmadinejad Z, Shaikh H, Yousefi R, Yarmohammadi L, et al. The changes of metabolic profile and weight during Ramadan fasting. Singapore Med J 2006;47(5):409-14.

24. Kautzky-Willer A, Kosi L, Lin J, Mihaljevic R. Gender-based differences in glycemic control and hypoglycemia prevalence in patients with type 2 diabetes: results from patient-level pooled data of six randomized controlled trials. Diabetes Obes Metab 2015;17:533-40.

25. Almalki MH, Alshahrani F. Options for controlling type 2 diabetes during Ramadan. Front Endocrinol 2016; 7:32.

26. Salti I. Diabetes and Ramadan Study Group Efficacy and safety of insulin glargine and glimepiride in subjects with Type 2 diabetes before, during and after the period of fasting in Ramadan. Diabet Med 2009; 26: 1255-61.

27. Cesur M, Corapcioglu D, Gursoy A, Gonen S, Ozduman M, Emral R, et al. A comparison of glycemic effects of glimepiride, repaglinide, and insulin glargine in type 2 diabetes mellitus during Ramadan fasting. Diabetes Res Clin Pract 2007; 75: 141-7.

28. Devendra D, Gohel B, Bravis V, Hui E, Salih S, Mehar $\mathrm{S}$, Hassanein M. Vildagliptin therapy and hypoglycaemia in Muslim type 2 diabetes patients during Ramadan. Int J Clin Pract 2009;63(10):1446-50.

29. Yarahmadi S, Larijani B, Bastanhagh M, Pajouhi M, Baradar JR, Zahedi F, et al. Metabolic and clinical effects of Ramadan fasting in patients with type II diabetes. J Coll Physicians Surg Pak 2003; 13(6):329-32.

30. Al-Arouj M, Assaad-Khalil S, Buse J, Fahdil I, Fahmy M, Hafez S, et al. Recommendations for management of diabetes during Ramadan. Diab Care 2010; 33(8):1895-902.

31. Al Hourani HM, Atoum MF, Akel S, Hijjawi N, Awawdeh S. Effects of Ramadan fasting on some haematological and biochemical parameters. Jordan J Biol Sci 2009;2(3):103-8. 